ulum vitae and personal statement. There are multiple chapters devoted to the interview process that address attire, intelligent questions to ask, who the right people to ask are, and questions that the student may be asked (with answers!). The book even goes as far as discussing how to best pack a suitcase as the student heads out for interviews to avoid wrinkling the clothes inside!

A very strong segment of the book addresses the subsequent match process. This is an area of much bewilderment for most medical students, often with limited help from school administrators. The book does an excellent job of explaining the process and the important steps along the way, and will give the student a great head start over fellow classmates. In addition, it discusses the different match programs that are used, how they work, and a timeline of how to proceed when participating in each match system.

Many other topics are discussed in this book, including finding a mentor, setting a fourth-year schedule, and the pros and cons of doing an "away rotation." In addition, there are many charts and tables that provide the student with the opportunity to complete a personal analysis of their goals and expectations in medicine and residency. These tools help the student make more objective decisions and will serve as great tools for submitting rank-order lists to the match. New with this edition is a companion disk that contains these charts and that will do many of the calculations for the student. Unfortunately, the disk is not included with the book and costs an extra US \$12 to purchase.

Overall, this is an excellent book that I would highly recommend to medical students at any point in their medical school training. Iserson does a great job of leading students through the many hurdles on the path to residency that are often very confusing and overwhelming. Although the cost may seem steep, this book will probably be used more than most of the curriculum textbooks used in the first 2 years of school that cost twice as much, so it is money very well spent.

Spencer Havens, MS, ATC Milwaukee, WI, USA

\section{Wildlife of the Galapagos Islands}

Julian Fitter, Daniel Fitter, and David Hosking

Princeton, NJ: Princeton University Press, 2000

US \$19.95, 255 pages, 400 illustrations, softcover

The Galapagos Islands are a magical place, a place where every day of exploration reveals new and beautiful terrain, fascinating land creatures, colorful birds, and unique aquatic species. The archipelago consists of 33 independently named islands officially known as El Archipelago de Colon. The Islands are a province of Ecuador and are located due west of the country, straddling the equator.

I have been fortunate enough to spend some time in the Galapagos, and I still remember the excitement of waking each day onto the front of the boat, feeling the morning sun on my face and the salt spray in the air, and seeing an island of new geographical formations or a school of feeding dolphins or a whale breaching in the distance. Each of the islands had its own distinct ecosystem, replete with unique plants, animals, birds, and aquatic life. Each stop was a discovery in nature, from the namesake Galapagos tortoises, to the blue-footed booby, to the brightly colored Sally Lightfoot crabs, to the noisy and ever-present Galapagos sea lions.

Wildlife of the Galapagos is a field guide to the most commonly encountered species in the islands, including birds, mammals, reptiles, invertebrates, plants, and coastal and marine life. The book begins with a short introduction that includes a few pages on conservation efforts and a brief summary of basic photography techniques. The meat of the book follows in the next 180 pages, which are divided into the wildlife sections listed above. Each species is identified by its common name followed by its technical scientific name. A few sentences to a few paragraphs follow, depending on the species' prominence. The text includes each species "vital statistics," along with a few key facts and a summary of the best viewing locations. There are more than 400 color photographs and sketches to accompany the text. The book concludes with a brief history of the islands, some information on its most notable weather patterns (especially El Niño), and a few more pages on conservation work. The last 25 pages consist of a simple guide to travel, broken down by islands and including a list of the top attractions and notable wildlife on each. The book concludes with a bibliography, a short glossary, and an index that includes scientific and common names.

This book is not meant to be a comprehensive text; rather, it serves well in its role as a pocket guide. Its 255 pages, light weight, and small size $(4.5 \times 5.5$ inches $)$ should make it a welcome addition to any backpack while visiting the islands.

Overall, this is an excellent pocket guide for travelers to the islands. I wish that I had had one when I visited the Galapagos, and I would readily recommend it to those who are on their way.

Stephen J. Liu, MD

Palo Alto, CA, USA 